\title{
Flood season segmentation and scheme optimization
}

\author{
KE ZHOU ${ }^{1}$ \\ ${ }^{1}$ North-China University of Water Conservancy and Electric Power
}

January 25, 2021

\begin{abstract}
River flood season segmentation is a significant measure for flood prevention. The objective of this study is to carry out theoretical analysis on flood season segmentation methods and put forward a framework for reasonable flood season segmentation. The proposed framework consists of a Fisher optimal partition method for determining the optimum numbers of the sub-seasons, an ensemble approach for segmenting a defined flood season, and a Non-parametric bootstrap combined with fuzzy optimum selection method (NB-FOS) for testing the rationality of the flood season staging schemes. The present research findings show that different methods could result in different staging schemes. It is proved through rational analysis that the staging scheme obtained by Probability change-point (PCP) is superior to others. The flood season of the downstream reach of Yellow River can be segmented into 3 sub-seasons, i.e. early flood season(Jun.01-July 20), main flood season (July 21- Sept.28), and late flood season (Sept.29- Nov.08). The segmentation results of the flood season should play active role in flood prevention.
\end{abstract}

\section{Hosted file}

flood_season_segmentation.pdf available at https://authorea.com/users/391551/articles/505618flood-season-segmentation-and-scheme-optimization 